\title{
Program Pengembangan Kewirausahaan Mahasiswa dan Alumni di Universitas Islam Darul Ulum Lamongan
}

\author{
Ali Shodikin', Wahyu Kyestiati Sumarno², Sutardi ${ }^{3}$, Ali Muhajir ${ }^{4}$ \\ Universitas Islam Darul Ulum ${ }^{1,2,3,4}$ \\ alishodikin@unisda.ac.id ${ }^{1}$, kyestiatisumarno@unisda.ac.id ${ }^{2}$, sutardi@unisda.ac.id ${ }^{3}$, \\ alimuhajir@unisda.ac.id ${ }^{4}$
}

\begin{abstract}
At this time, a lot of news about unemployment of higher education graduates became a special concern for the campus as the organizer. The solutions adopted include entrepreneurship education programs for students and graduates. But often entrepreneurship education programs that are carried out are not continuous and sporadic in order to obtain less optimal results. The entrepreneurship development program aims to provide entrepreneurship guidance for students and alumni of Universitas Islam Darul Ulum by prioritizing the concept of sustainable training and coaching and adjusting tenant issues. This program used a three-phase of Participatory Action Learning System (PALS) approach, namely awareness, entrepreneurship capacity building, and institutionalization. The results obtained that this program provided improvements in tenant management, produced science and technology-based products and formed cooperation with related parties. With regard to these results, we recommend that higher education institutions be able to carry out similar entrepreneurship development program. Further studies are recommended to focus more on the impact of entrepreneurship development program implementation on enthusiasm, anxiety, and readiness in entrepreneurship.
\end{abstract}

Keywords: Entrepreneurship Development Program; Students and Alumni; Universitas Islam Darul Ulum.

\begin{abstract}
Abstrak
Di masa ini, banyak pemberitaan tentang pengangguran lulusan pendidikan tinggi menjadi perhatian tersendiri bagi kampus sebagai penyelenggaranya. Solusi yang ditempuh di antaranya adalah program pendidikan kewirausahaan bagi mahasiswa dan lulusan. Namun seringkali program pendidikan kewirausahaan yang dilakukan tidak berkesinambungan dan sporadis sehingga diperoleh hasil yang kurang optimal. Program pengembangan kewirausahaan (PPK) ini bertujuan untuk memberikan pembinaan kewirausahaan bagi mahasiswa dan alumni Universitas Islam Darul Ulum dengan mengedepankan konsep pelatihan dan pembinaan berkesinambungan serta menyesuaikan masalah tenant. Program ini menggunakan pendekatan Participatory Action Learning System (PALS) dengan tiga fase yakni penyadaran kewirausahaan (awareness), pengkapasitasan dan pendampingan kewirausahaan (entrepreneurship capacity building), dan pelembagaan (institutionalization). Diperoleh hasil bahwa program ini memberikan perbaikan dalam pengelolaan tenant, menghasilkan produk berbasis iptek dan terbentuknya kerjasama dengan pihak-pihak terkait. Berkenaan dengan hasil ini, kami menyarankan kepada lembaga pendidikan tinggi untuk dapat melaksanakan kegiatan pengembangan kewirausahaan serupa.
\end{abstract}


Studi lebih lanjut disarankan lebih fokus kepada dampak pelaksanaan PPK terhadap semangat, kecemasan, dan kesiapan berwirausaha.

Kata Kunci: Program Pengembangan Kewirausahaan; Mahasiswa dan Alumi; Universitas Islam Darul Ulum.

\section{A. PENDAHULUAN}

Kesadaran perguruan tinggi akan pentingnya pengembangan jiwa kewirausahaan bagi mahasiswanya telah mulai tumbuh dan berkembang. Hal ini dapat dilihat dari maraknya programprogram yang dilaksanakan untuk memupuk jiwa kewirausahaan mahasiswa, alumni, maupun khalayak umum seperti seminar kewirausahaan, kuliah kewirausahaan, pameran produk, hingga program pembinaan kewirausahaan. Hal yang sama juga dilakukan oleh Pemerintah untuk menyokong program-program kewirausahaan, seperti program kreativitas mahasiswa (Direkorat Kemahasiswaan, 2017), program mahasiswa wirausaha berbasis iptek (Direktorat Jenderal Penguatan Inovasi, 2017), dan iptek bagi kewirausahaan (Direktorat Riset dan Pengabdian Masyarakat, 2017). Hal tersebut secara berkesinambungan dilakukan setiap tahunnya.

Universitas Islam Darul 'Ulum Lamongan sebagai institusi perguruan tinggi juga tengah mengembangkan program kewirausahaan bagi mahasiswa, alumni dan masyarakat umum melalui seminar kewirausahaan, program desa binaan, pembinaan kreativitas mahasiswa, kompetisi kewirausahaan mahasiswa, kuliah kewirausahaan, pelatihan-pelatihan terkait kewirausahaan dan pameran kewirausahaan sebagaimana dilakukan perguruan tinggi lainnya. Namun dirasa pelaksanaan pembinaan yang ada masih belum dilakukan secara berkesinambungan antara satu program dengan program lainnya dan tidak menyesuaikan permasalahan masing-masing individu wirausahawan atau calon wirausahawan. Padahal pembinaan yang kontinu dan berkesinambungan akan lebih berpotensi menghasilkan wirausahawan yang matang.

Berdasarkan penelitian pendahuluan yang dilakukan, permasalahan yang dihadapi oleh calon wirausahawan dan wirausahawan antara lain pemunculan ide, inovasi produk, sumberdaya, menejemen, pemasaran, produksi, pemodalan, pengemasan, hingga perijinan. Masalah yang muncul umumnya beragam dan berbeda-beda untuk masing-masing orang. Kebanyakan dalam menjalankan usahanya, mereka belum menerapkan iptek untuk meningkatkan usahanya.

Melihat permasalahan di atas, keberadaan Program Pengembangan Kewirausahan (PPK) dengan konsep pelatihan dan pembinaan berkesinambungan serta menyesuaikan masalah wirausahawan dan calon wirausahawan sangatlah penting. Program ini mengombinasikan antara pemberian teori dan praktek di lapangan. Metode pengoperasiannya mengikuti prinsip "learning by doing" yaitu mengajak para tenant untuk memperhatikan, mempelajari, mencoba membuat desain dan melakukan/ menjalankan produksi, turut serta menangani pemasaran, dan melakukan evaluasi terhadap seluruh aktivitas yang telah dijalankan (Hackathorn, 2011). Penerapan pembinaan dengan sistem praktik 
terbukti berhasil meningkatkan usaha mahasiswa menjadi wirausaha mandiri (Parwiyanti dkk., 2012; Arief dkk., 2016; Sulitiyowati dkk., 2016), disamping pemberian teori juga penting (Küttim dkk, 2014). Harapan dari penggunaan metode ini adalah agar para peserta dapat meresapi proses pembuatan desain, produksi hingga pemasaran, sehingga pada akhirnya akan mudah untuk mengadopsi hal-hal yang telah dialami di PPK untuk dibuat dan dikembangkan di lingkungan masingmasing. Jadi, peranan PPK adalah sebagai tempat pendadaran terhadap para mahasiswa dan alumni Universitas Islam Darul Ulum agar jiwa wirausaha mereka menjadi sebuah sikap wirausaha yang mandiri.

Sasaran program ini adalah mahasiswa dan alumni yang melakukan atau akan melakukan wirausaha yang disebut sebagai tenant yang berasal dari mahasiswa penerima program kreativitas mahasiswa bidang kewirausahaan dan sejenisnya, mahasiswa perintis usaha baru, dan alumni yang sudah memiliki usaha. Target program ini adalah minimal lima wirausaha baru mandiri berbasis iptek per tahun yang siap beraktivitas di masyarakat baik individu atau kelompok.

\section{B. PELAKSAAAN DAN METODE}

Program pengembangan kewirausahaan (PPK) ini dilaksanakan di lingkungan Universitas Islam Darul 'Ulum Lamongan dan sekitarnya. Program ini merupakan program berkelanjutan tahun 2017-2019 dan untuk periode 2018 ini dilaksanakan pada bulan Maret-Agustus. Sasarannya adalah 20 tenant baik individu maupun kelompok mahasiswa dan alumni yang berasal dari mahasiswa penerima program kreativitas mahasiswa bidang kewirausahaan dan sejenisnya, perintis usaha baru, dan yang sudah memiliki usaha.

Metode pendekatan Participatory Action Learning System (PALS) dipilih dalam PPK ini dikarenakan metode ini menekankan pelibatan peserta secara aktif dalam proses pembelajaran sehingga membentuk suatu sistem interaksi pembelajaran yang partisipatif, baik secara personal maupun komunal. Metode ini terdiri dari tiga fase, yakni (1) fase penyadaran kewirausahaan (awareness), (2) fase pengkapasitasan dan pendampingan kewirausahaan (entrepreneurship capacity building), dan (3) fase pelembagaan (institutionalization). Secara diagramatik metode PALS ditunjukkan pada berikut.

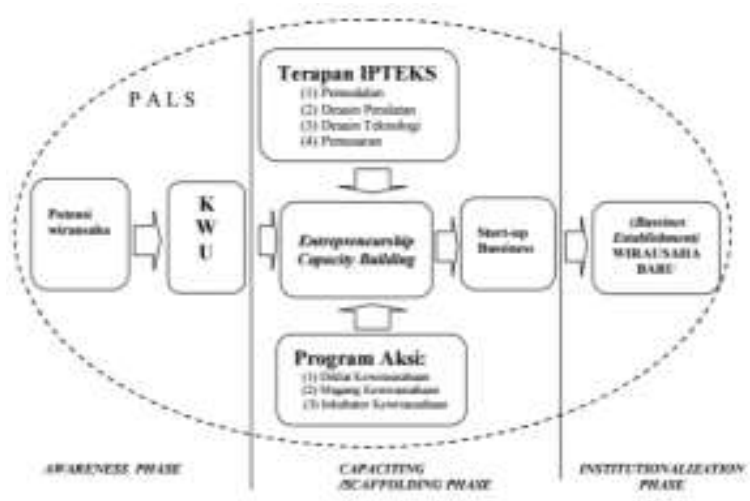

Gambar 1. Metode Participatory Action Learning Systems (PALS)

Fase penyadaran bertujuan untuk memunculkan motivasi wirausaha dan penjaringan calon peserta program pengembangan kewirausahaan dari mahasiswa dan alumni melalui penjaringan potensi wirausaha melalui kegiatan seminar kewirausahaan (KWU). Seleksi dilakukan pasca pelaksanaan KWU.

Fase pengkapasitasan dan pendampingan kewirausahaan (entrepreneurship capacity building) merupakan tahapan yang paling panjang dalam program ini. Tujuan fase ini adalah memberikan 
keterampilan kepada pada tenant supaya mampu melaksanakan usahanya secara mandiri pasca pelaksanan program PPK. Fase ini dilaksanakan dalam bentuk pertemuan tatap muka, praktek langsung, dan pendampingan. Dalam pelaksanaannya dilakukan dalam 10 kali pertemuan yang disajikan pada Tabel 1 .

Tabel 1. Materi fase pengkapasitasan dan pendampingan kewirausahaan (entrepreneurship capacity building)

\begin{tabular}{cc}
\hline Pertemuan & Materi \\
\hline 1 & Business model canvas, evaluasi ide \\
\hline 2 & $\begin{array}{c}\text { Analisa value proposition dan } \\
\text { customer segment }\end{array}$ \\
\hline 3 & $\begin{array}{c}\text { Strategi pemasaran dan } \text { customer } \\
\text { relationship management }\end{array}$ \\
\hline 4 & $\begin{array}{c}\text { Aspek mekanisme operasional dan } \\
\text { proses bisnis usaha }\end{array}$ \\
\hline 5 & $\begin{array}{c}\text { Analisa keuangan usaha dan } \\
\text { legalitas usaha }\end{array}$ \\
\hline 6 & Konsultasi dan praktek pembuatan \\
karya
\end{tabular}

Selanjutnya fase pelembagaan bertujuan untuk memberikan penguatan pelembagaan tenant. Kegiatan di dalamnya berupa pembentukan kerjasama, pengurusan ijin usaha dan P-IRT produk tenant.

\section{HASIL DAN PEMBAHASAN}

\section{Penyadaran Kewirausahaan}

Kegiatan "sekolah kewirausahaan" dalam bentuk seminar dipilih sebagai perwujudan dari penyadaran kewirausahaan. Bentuk seminar dipilih karena mampu menampung lebih banyak peserta. Melalui kegiatan sekolah kewirausahaan ini peserta diberikan materi tentang motivasi pentingnya berwirausaha dari pengalaman pribadi owner CV. Polita Nusantara dan penyusunan rencana bisnis oleh Ketua Pusat Pengembangan Karir dan Kewirausahaan UNISDA. Kegiatan ini diikuti oleh 198 peserta dari mahasiswa dan alumni. Terlihat antusiasme peserta dalam mengikuti kegiatan, baik saat penyampaian materi, diskusi, tanya jawab hingga pembutan rencana bisnis.

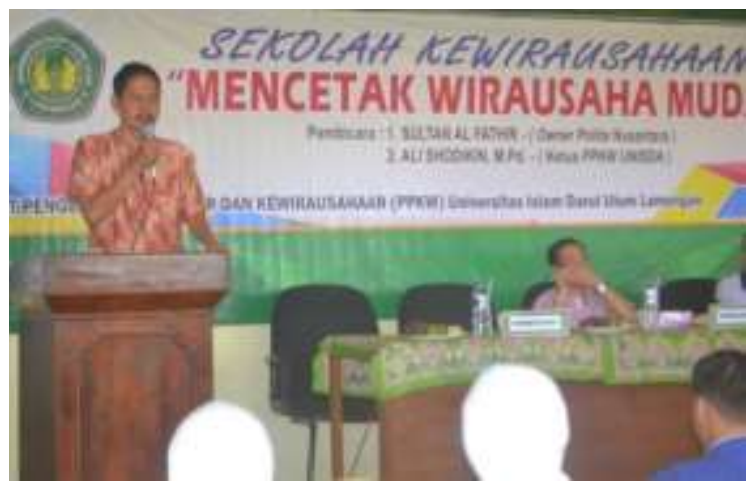

Gambar 2. Sekolah Kewirausahaan

Diakhir kegiatan diberikan penugasan berupa penyusunan bisnis plan untuk menentukan 20 peserta yang lolos ke tahap pengkapasitasan dan pendampingan.

\section{Pengkapasitasan dan Pendampingan}

Sebagai hasil dari fase pengkapasitasan dan pendampingan diperoleh 20 jenis usaha yang terdiri dari 15 produk dan 5 jasa. Produk-produk yang dihasilkan antara lain tas rajut "Niswa", keripik tales "Kriies", mie lidi "Mitusa", bross dan pernik "Hello Kitty", batik "Nawa Kartika", kopi lantoro, foozen food "Mandiri Barokah" dan samiler "Bahtiar". Sedangkan produk jasa antara lain jasa sablon "Tigo Sedulur", jasa kaligrafi, jasa pemasaran online. 

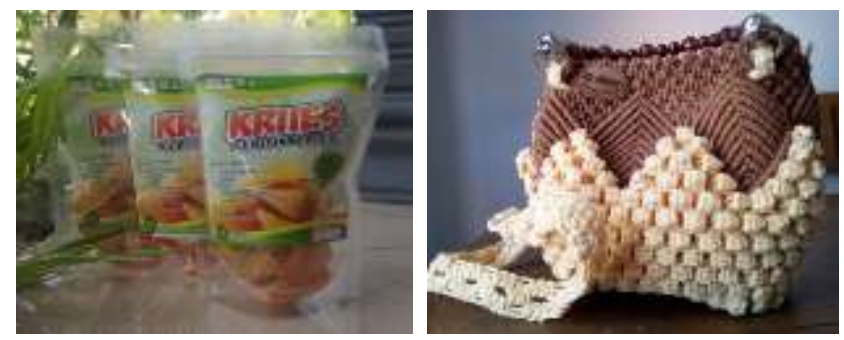

Gambar 3. Beberapa produk hasil PPK

Untuk membangun keterampilan produksi, tenant juga diberikan praktek pembuatan produk. Dalam kegiatan ini, karena beragam produk tenant yang ada, pelaksanaan workshop terbatas pada produk makanan. Kegiatan praktik lainnya yang dilakukan adalah kunjungan industri UMKM dan magang di industri.

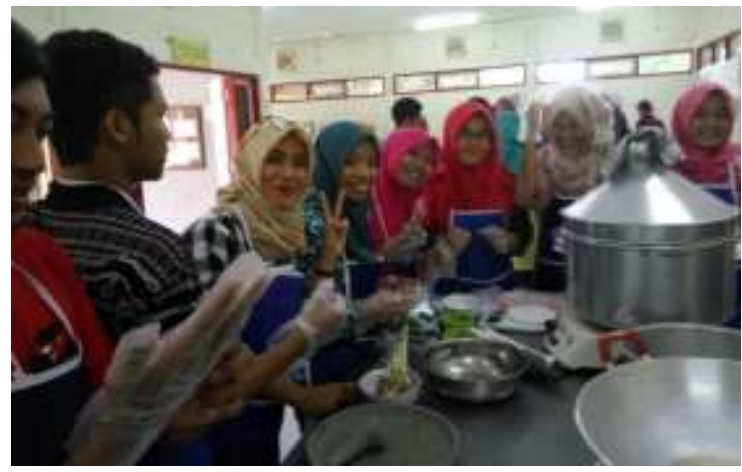

Gambar 4. Pelatihan pembuatan produk

Selanjutnya pendampingan bisnis bertujuan membantu dan membimbing proses menyusun manajemen, pemasaran, produksi, memecahkan masalah-masalah yang dihadapi oleh para tenant sehubungan dengan bisnis yang dijalankannya. Sifat bantuannya adalah konsultasi yang dilakukan secara sinambungan dengan memegang prinsip manajemen kewirausahaan. Penelitian pasar juga merupakan salah satu kegiatan pada fase ini yang bertujuan menganalisis peluang dan potensi pasar dalam rangka penciptaan dan pengembangan usaha bagi tenant.
Pembinaan pemasaran yang dilakukan tidak hanya pemasaran secara konvensional (offline), tetapi juga melalui online. Pembinaan dalam pembuatan dan pemasaran via facebook dan instagram dilakukan untuk meningkatkan peluang pasar. Selain itu, PPK memfasilitasi tenant untuk memasarkan produknya melalui kegiatan pameran baik diselenggarakan oleh UNISDA maupun di luar UNISDA, seperti UNISDA Expo, Bazar wisuda, pemeran produk unggulan kewirausahaan mahasiswa.

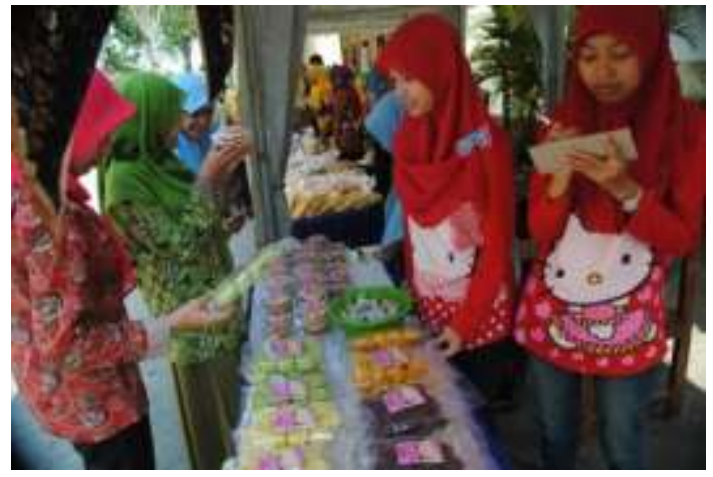

Gambar 5. Pameran kewirausahaan produk PPK

\section{Pelembagaan}

Fase pelembagaan menghasilkan beberapa kerjasama diantaranya Universitas Islam Darul Ulum dengan Dinas Perindustrian dan Perdagangan Kabupaten Lamongan, Dinas Kesehatan, Asosiasi Perajin Kabupaten Lamongan. Selain itu, lima produk hasil PPK juga sudah memiliki P-IRT.

Berdasarkan pelaksanaan program pengembangan kewirausahaan, program ini memberikan perbaikan dalam pengelolaan tenant, menghasilkan produk berbasis iptek dan terbentuknya kerjasama dengan pihakpihak terkait. Pelaksanaan program pengembangan kewirausahaan di tingkat perguruan tinggi lain juga menghasilkan hasil yang sama memuaskan (Lifang, 2012; Malach dan Malach, 2014; Othman dan 
Nasrudin, 2016; Shodikin dkk., 2017; Zhang, 2014), namun perlu diperhatikan terkait aspek pendukung dan penghambat kewirausahaan seperti kecemasan, semangat dan kesiapan tenant.

\section{PENUTUP}

\section{Simpulan}

Program Pengembangan Kewirausahaan dengan pendekatan Participatory Action Learning System (PALS) terbukti memberikan perbaikan dalam pengelolaan tenant. Tiga fase yang dijalankan yakni penyadaran kewirausahaan (awareness), pengkapasitasan dan pendampingan kewirausahaan (entrepreneurship capacity building), dan pelembagaan (institutionalization) mampu meningkatkan motivasi dan pemahaman konsep kewirausahaan, meningkatkan kemampuan dalam manajemen, marketing usaha, serta kemampuan membuat produk dan kemasannya.

\section{Saran}

Pelaksanaan program pengembangan kewirausahaan ini merupakan program yang berkesinambungan dan tidak dapat selesai dalam satu periode. Pengawasan harus tetap dilakukan meskipun program sudah selesai. Program pengembangan kewirausahaan ini pelaksanaannya dapat diduplikasi sebagai referensi pendidikan kewirausahaan di tingkat perguruan tinggi.

\section{Ucapan Terima Kasih}

Ucapan terimakasih disampaikan kepada Direktorat Riset dan Pengabdian Masyarakat, Direktorat Jenderal Penguatan Riset dan Pengembangan, Kementerian Riset, Teknologi, dan Pendidikan yang telah memberikan pendanaan dan kepercayaan untuk melaksanakan Program Pengembangan
Kewirausahaan (PPK) tahun 2018, LPPM, dan pimpinan Universitas Islam Darul Ulum yang telah memberikan dukungan, fasilitas dan moril dalam pelaksanaan program.

\section{E. DAFTAR PUSTAKA}

Arief, M.R., Astuti, P., \& Andriyanto, T. 2016. Ipteks Bagi Kewirausahaan (IbK) di Universitas Nusantara PGRI Kediri. Jurnal Dedikasi, Vol. 13, 1-8.

Direktorat Kemahasiswaan. 2017. Pedoman Program Kreativitas Mahasiswa Tahun 2017. Jakarta: Direktorat Kemahasiswaan Direktorat Jenderal Pembelajaran dan Kemahasiswaan Kementerian Riset, Teknologi dan Pendidikan Tinggi.

Direktorat Jenderal Penguatan Inovasi. 2017. Panduan Program Calon Perusahaan Pemula Berbasis Teknologi Dari Perguruan Tinggi (Calon Startup) Tahun 2018. Jakarta: Kementerian Riset Teknologi dan Pendidikan Tinggi.

Direktorat Riset dan Pengabdian Masyarakat. 2017. Panduan Penelitian dan Pengabdian kepada Masyarakat Edisi XI Tahun 2017. Jakarta: Direktorat Riset dan Pengabdian Masyarakat, Kementerian Riset Teknologi dan Pendidikan Tinggi.

Hackathorn, J. et.al. 2011. Learning by Doing: An Empirical Study of Active Teaching Techniques. The Journal of Effective Teaching, Vol. 11, No. 2, 40-54. 
Küttim, M., Kallaste, M., Venesaar, U. \& Kiis, A. 2014. Entrepreneurship Education at University Level and Students' Entrepreneurial Intentions. Procedia - Social and Behavioral Sciences. Vol. 110, 658-668.

Lifang, L. 2012. The Investigation and Analysis of Chinese University Students' Current Situation of Entrepreneurship and the Countermeasures--The Reflection from a Special Investigation in Pearl Delta in China. International Education Studies. Vol. 5, No. 2, 105112.

Malach, S. E., \& Malach, R. L. 2014. Start Your Own Business Assignment in the Context of Experiential Entrepreneurship Education. Journal of Higher Education Outreach and Engagement. Vol. 18, No. 1, 169-186.

Othman, N., \& Nasrudin, N. 2016. Entrepreneurship Education Programs in Malaysian Polytechnics. Education \& Training. Vol. 58, 882-898. https://doi.org/10.1108/ET-11-20140136.

Parwiyanti, Ermanovida, \& Ammar, M. 2012. Implementasi Program Iptek bagi Kewirausahaan di Universitas Sriwijaya Tahun 2012. Prosiding Seminas Competitive Advantage. Vol. 1, No. 2.

Shodikin, A., Sutardi, Muhajir, A., \& Sumarno, W. K. 2017. Iptek bagi Kewirausahaan di Universitas Islam Darul Ulum, Prosiding Senasif 2017. 316-321.
Sulistiyowati, W., Agustini, I., \& Fitriyah, H. 2016. Peningkatan Kapasitas Entrepreneurship melalui Pelatihan dan Magang Bagi Tenant di Universitas Muhammadiyah Sidoarjo. Jurnal Pengabdian pada Masyarakat. Vol. 1, No. 1, 1-5.

Zhang, M. 2014. Study on Enterprise Education System for Undergraduates in Universities. Higher Education Studies. Vol. 4, No. 6, 58-61. 